\title{
Directing the technology intelligence activity: An 'information needs' template for initiating the search
}

\author{
Clive Kerr ${ }^{*}$, Robert Phaal \\ Institute for Manufacturing, University of Cambridge, Cambridge, CB3 OFS, UK
}

\begin{abstract}
In technology-intensive sectors, strategic planning requires relevant and timely information about new/emerging technologies - this is a critical input. Therefore, technology intelligence activities should be directed to capture and deliver pertinent technological information. However, there is a distinct lack of tools for helping organizations to determine what constitutes useful/appropriate information for their needs. To address this issue, an 'information needs' template has been developed to support the process of eliciting and articulating meaningful search queries to guide those who will conduct and provide the necessary intelligence. The use of the template also acts as a means of priming the technology intelligence as it identifies and points to potentially useful sources of knowledge. It covers the spectrum of sources from leveraging internal information, through spanning organizational boundaries to access external sources across the specific industry and neighboring industries, to more distant fields of knowledge. Additionally, the template has sections for distinguishing 'who to watch' versus 'who to talk to'. The deployment of the template can be integrated with roadmapping, using the roadmap landscape to feed hotspots/themes/gaps/white spaces into the template, which are then unpacked to determine the information needs of the organization.
\end{abstract}

\section{Keywords}

Technology intelligence; Roadmapping; Strategic planning; Technology management

\section{Introduction}

Strategy-making and planning is knowledge-intensive and requires organizations to have an appropriate level of foresight and understanding of market-, competition- and technology-specific factors. Acquiring such information about the changing business environment is an important input for strategic planning (Lozada and Calantone, 1996). In regards to information gathering, it requires an organization to proactively collect relevant data through mechanisms such as scanning the business landscape (Mietzner and Reger, 2009). Therefore, one of the key activities for the provision of information for strategic planning is 'technology intelligence'. Decision-makers inevitably have gaps in their knowledge relating to technologies and therefore have a critical need for the provision of relevant intelligence as an input to the planning process (Kerr et al., 2006). Technology intelligence is defined by Kerr et al. (2006) as the capture and

\footnotetext{
* Corresponding author at: Centre for Technology Management, Institute for Manufacturing, University of Cambridge, 17 Charles Babbage Road, Cambridge, CB3 0FS, UK.

E-mail addresses: civk2@cam.ac.uk (C. Kerr), rp108@eng.cam.ac.uk (R. Phaal).
} 
delivery of information relating to technologies and it allows an organization to develop an awareness of both technological opportunities and threats, including making an assessment of the state-of-the-art and profiling related trends within a technology domain.

Within the field of technology and innovation management, there are numerous examples of approaches to technology intelligence and these primarily take the form of industrial case studies (Arman and Foden, 2010; Lichtenthaler, 2003, 2004a, 2004b, 2007; Mortara et al., 2009a, 2010). In terms of actual tools, the literature is predominately orientated to data/text/document-mining (Lee et al., 2011, 2012; Porter 2005; Porter and Newman, 2011; Veugelers et al., 2010; Yoon, 2008), with patents being an obvious source of intelligence (Park et al., 2013; Yoon and Kim, 2012). In regards to the specification or definition of information needs, Rohrbeck (2010) identifies that this issue is problematic, especially with the application of automated data-mining tools, which often lack any meaningful involvement with the decisionmakers/key stakeholders and leads to the production of information with "little internal acceptance". Lozada and Calantone (1996) highlight that "some wanted information is not received and some information received is not wanted". One of the unique toolsorientated papers is that of Mortara et al. (2009b) which looks at a broader range of tools (including people and infrastructure elements) in an attempt to generate a toolbox for technology intelligence. Perhaps, one of the most well-known tools is the 'technology radar'. This was originally developed by Rohrbeck et al. (2006) to help disseminate information by providing an overview of potential technologies and their relevance to an organization. It takes the form of a radar screen and reports the technologies against development phases, or maturity levels, across a number of technological fields. The technology radar has been applied in a number of documented cases (Golovatchev et al., 2010; Schuh et al., 2011; Veugelers et al., 2010). Additionally, there are other variants of the concept such as the 'opportunity landscape' (Savioz and Blum, 2002). However, it must be noted that the tool-orientated literature appears to be limited to the mechanics of data collection/analysis, especially in regards to data-mining, and a specific form of application for information dissemination in regards to the technology radar. There is a lack of research on formalizing the link between technology intelligence and strategic planning. Additionally, there is an apparent absence of tools to direct the technology intelligence activity and help initiate the search processes by providing a guide to the data/information needs of planners and decision-makers.

"Defining an organization's actual intelligence needs, and doing so in a way that results in the production of intelligence that management feels compelled to act on", is according to Herring (1999) one of the most elusive of goals. As acknowledged by Citroen (2011), the 'information' perspective in strategy-making is largely neglected in the literature. A key question is: what information needs to be collected, analyzed and disseminated? (Kerr et al., 2006). Even though this question forms a fundamental and critical input for initiating the technology intelligence activity, it has not been adequately addressed by practical, yet theoretically robust, management tools. This aspect is termed the 'specification of information' by Mietzner and Reger (2009), who highlight the need for supportive linkages between the information gathering activities and strategic planning - especially at the beginning of the process where the definition of requirements is vital. From the domain of competitive intelligence (CI), there is the established KIT (Key Intelligence Topics) process which is used at the beginning of a 
CI program to help companies identify and prioritize the intelligence needs of senior managers (Herring, 1999). Underlying the KIT process is a series of open-ended and non-directive interviews conducted with the key decision-makers by CI specialists (Herring, 1999; Francis and Herring, 1999); the intelligence needs are then "synthesized by the interviewer over time as the interviews are completed" (Francis and Herring, 1999). Thus, the KIT process does require and rely upon a significant degree of both experience and competence by intelligence specialists. In adopting the KIT process from competitive intelligence across into the field of technology and innovation management for technology intelligence, the burden and reliance of specialist knowledge should be lowered. Additionally, there is the opportunity to enhance dialogue and allow the process to be more integrative by heightening the level of direct engagement between organizational stakeholders. To help address such issues, this paper reports on the development of a management tool which aims to support the specification of the information requirements from key stakeholders and thus direct the technology intelligence activity. The tool takes the form of a template, which can be deployed in workshops or team meetings, and its aim is the capture of the information needs relating to a given technology or technological domain. This can then be used to initiate the search processes through appropriate technology intelligence mechanisms and channels. The 'information needs' template provides a linking point between strategic planning and technology intelligence. To further formalize the link, the application of the template can be integrated with roadmapping - which is widely regarded as a key tool in strategic planning in technology-intensive sectors. This integration will be presented and the associated process considerations discussed. To demonstrate the use of the template, a 'real world' example is provided where the tool was tested with a group of industrial practitioners from a multinational energy company, highlighting the potential outputs that can be achieved.

\section{Theoretical perspectives and practitioner considerations}

The development of the 'information needs' template was informed by the theoretical lenses of: the 'use of knowledge as a resource' and the concept of 'search' in knowledge exploration from organizational learning. Additionally, to heighten the potential utility from applying the template and ensure the appropriateness of its deployment by industrial users, a psychosocial perspective was taken together with the implementation of several key principles for developing industrially relevant strategic technology management tools.

Dervin (1998) asserts that we "live in a world of gaps" and as a reality changes across a given space or timeframe then, for sensemaking, we should be concerned with the 'gappy' parts. Herring (1999) found that a company's intelligence gaps can be typically assigned against three basic categories:

- Strategic issues/decisions/actions - e.g. likely future business environment; acquisition possibilities (Herring, 1999; Weiss, 2002).

- Early-warnings/perceived threats - e.g. technological surprise, shifts and areas of possible breakthrough; deregulation; unexpected alliances, entry of a new/foreign competitor into the market or new classes of competitor (Aspinall, 2011; Ettorre, 1995; Herring, 1999; Weiss, 2002). 
- Descriptions/characteristics/profiling of key players - e.g. product benchmarking and changes in mix/offering; personnel changes at a competitor firm (Bartes, 2014; Ettorre, 1995; Herring, 1999; Weiss, 2002).

Such 'gaps' equates to 'white spaces' and results in leading questions being asked which can then be used to direct the technology intelligence activity by, in effect, setting the contextual frame and search parameters. The front-end of technology intelligence is concerned with the capture of information (Kerr et al., 2006) and where the search is orientated to finding, or unearthing, relevant information which can then be analyzed and disseminated to managers to inform their strategic planning activities. This view recognizes knowledge as a resource and that it provides a critical input to the planning process.

March's (1991) seminal paper on exploration and exploitation included the concept of 'search' under the exploration category. This concept is often referred to as knowledge exploration and/or knowledge search. In reference to technology intelligence, the activity can be regarded as a specific form of exploration or search since its purpose is aimed at gathering information orientated to technological opportunities (and threats). The sources of information to be searched can be local, for example internal to an organization, or distant, i.e. other industries (Kerr et al., 2006; Lin and Li, 2013; Miller et al., 2007). Thus, an effective search strategy must involve both sources. Local knowledge can be mined and trawled (Kerr et al., 2006). This local search presents a familiar space where existing combinations of knowledge are sought within organizational boundaries (Miller et al., 2007). It includes the perspectives of firm divisionalization, i.e. across both divisional and geographic boundaries, and intrafirm networks (Miller et al., 2007), e.g. the diversity which exists within supply chains or technological domains within the relevant industrial sector. In contrast, distant knowledge must be targeted and scanned (Kerr et al., 2006). This distant space is typically across competitive boundaries spanning through into other industries and so can leverage open innovation practices. Miller et al. (2007) highlights that "new combinations of distant knowledge may produce path-breaking innovations". Linked to the concepts of local and distant are the associated search variables of 'depth' and 'scope'. According to Katila and Ahuja (2002), search depth refers to the degree to which an organization revisits its prior knowledge and reuses its existing information; whereas search scope describes how widely a firm explores new sources. These elements have been encapsulated and embedded into the structure of the 'information needs' template.

To appropriately prime the searching of sources, there should be a specification (i.e. eliciting and understanding) of the information requirements for the intended recipients (e.g. management team/decision-makers). A needs-orientated perspective attempts to articulate what constitutes appropriate or relevant information and it is this aspect that is currently lacking research/tools within technology intelligence. The potential development of such tools can provide the opportunity to formalize an explicit link to strategic planning. In regards to the recipients, Nag and Gioia's (2012) model provides a helpful insight into a manager's conceptualization of the utility of knowledge resources. There is the concept of 'executive knowledge schemes' which focuses on the nature of valuable information as contrasted with a manager's interpretive framework. Of course, managers display patterns of variation in their beliefs about the significance and sources of useful knowledge (Nag and Gioia, 2012). So, for the technology intelligence activity, having executives not only discuss but also capture their opinions 
and have these both facilitated and consolidated in a helpful form (such as the 'information needs' template) would then better inform the direction of the search. Additionally, there is also the need to reflect on the relevance of sought information. Such a reflection must be made in regards to any potential application areas and other internal uses for that particular technology, or technological domain, which is to be explored through the technology intelligence activities. Nag and Gioia (2012) highlight the theme of 'significance' that represents what aspects of knowledge are deemed to be important. In the case of technology intelligence, this can be used to differentiate the technical/scientific issues versus, say, more commercial/market-related queries relating to a technology and then used to identify the pertinent questions from these dual perspectives. These aspects have also been encapsulated and embedded into the 'information needs' template.

Having positioned explorative search and information requirements with the relevant theoretical lenses, there is the pragmatic issue of an appropriate mode/mechanism of engagement for deploying the template-based tool. Karunakaran et al. (2013) emphasize the potential of people proactively working together to "understand and formulate an information need through the help of shared representations". In specific regard to the collaboration aspect, Shah (2014) highlights that many information-related activities such as 'search' are not recognized as collaborative tasks. One of the aims for developing the template, as presented in this paper, was to provide a structured representation that can facilitate and support the collaborative definition of information needs. This relates to the phase of 'problem formulation' in Karunakaran et al.'s (2013) conceptualization of 'collaborative information behavior'. For the application of the 'information needs' template in a collaborative setting by industrial practitioners, the strategy-as-practice perspective (Jarzabkowski et al., 2007) has informed the development of the tool by recognizing and positioning its deployment as a sociallyaccomplished activity. Therefore, the main mode of deployment is in group-based workshops and team meetings. In regards to the application of management tools in actual corporate settings, Kerr et al. (2013) state that "workshops are essentially an engagement mechanism for group interaction by structuring activities around using the tools for solving strategic problems". Thus, one of the key principles of tool deployment, under a strategy-as-practice lens, is that tools should be 'human-centric' that is, "a tool should provide the opportunity for individuals to participate and engage with one another leading to a co-created solution which embodies their meaningful collaboration and generates a useful product from the result of their social interaction" (Kerr et al., 2013). In specific regards to group-based activities, Brodbeck et al. (2007) highlight the following beneficial aspects:

- The identification and integration of individual viewpoints.

- The combining and integrating of different knowledge, ideas and perspectives.

According to Kerr et al. (2012), the socially situated environment of group workshops provides a psychosocial means to "cogitate, articulate and communicate". The 'articulate' verb is of key relevance as it underpins the functionality of the templatebased tool whereby it "encapsulates the actions of participants in expressing themselves, in terms of their mental models to provide context, and their ideas to provide content" (Kerr et al., 2012). Thus, the structure and information architecture of the template has been designed and developed to act as: (i) an interpretive schema (Kerr et al., 2012), for framing the workshop activity; and (ii) as a canvas, which is then populated with the 
content of participant discussions and interactions so capturing the information needs in order to direct the technology intelligence search. Another reason for deploying the 'information needs' template within a workshop is "the positive reinforcement that comes with attending a workshop (i.e. being given the opportunity to put forward your views) and actively participating (i.e. having your views recognized by your peers)" (Kerr et al., 2013). It is interesting to note that the well-established KIT process, which is formalized through a series of individual interviews, has been adapted by, as yet, a small number of researcher/practitioners into a workshop (Bartes, 2014; Clayton et al., 2011). Clayton et al. (2011) acknowledge that in-person/face-to-face workshops do indeed promote interaction and, very importantly, trigger the shared exploration of intelligence needs.

One final issue to consider for the utilization of a tool in a corporate setting, and its subsequent deployment in workshops/meetings, is the potentially powerful nature of its visual embodiment (i.e. the visual format/style and the execution of the visuals as a 'designed object'). In Kerr et al.'s (2013) principles for developing industrially relevant tools/toolkits, it is stated that "tools should have a visual form for both their application and their resulting output". This principle of visual embodiment recognizes that the visual format of the tool/template "has an important contribution to make in terms of providing a means for contextualization" and thus "provides a framing mechanism" (Kerr et al., 2013) for the group-based activities. From the strategy-as-practice perspective, tools/templates therefore "assume the status of an artifact; structuring information and providing grounds for interaction" (Spee and Jarzabkowski, 2009). A tool can then act as a 'focal point' which is helpful for facilitating the social interactions between participants (Spee and Jarzabkowski, 2009). Furthermore, tools/templates have the potential to ultimately act as 'boundary objects' (Kerr et al., 2013; Spee and Jarzabkowski, 2009). Fenton (2007) states that a boundary object's function is not only technical in nature but social - since it provides a means to share context and understanding. In regards to a visual template, Carlile (2002) acknowledges that such forms/methods have the ability to provide a shared format for solving problems among different participants/stakeholders, be mutually understood and help make the content/findings more shareable. Such a boundary object can then mobilize action (Kerr et al., 2013). This is especially relevant to the 'information needs' template as it will be used to initiate the technology intelligence activity (through providing directive queries that guide the search).

\section{A template for directing the technology intelligence activity}

Figure 1 presents the 'information needs' oriented template. It is intended to provide a theoretically-grounded and practical tool that can be deployed in a corporate setting. This template-based tool is designed to be a tangible and pragmatic means for addressing the challenge of 'information needs formulation' (Hansen and Järvelin, 2005); it can help prime the search processes, and associated mechanisms, within technology intelligence. The following sections will describe the key parts of the template; but before outlining the modes of deployment and describing the template elements, it must be stressed that the template is essentially a schema - it frames the 'information needs formulation' activity. It imparts meaning and structure to the knowledge being sought (Nag and Gioia, 2012). Figure 2 shows a typical example of a 
completed template. The use of the template can enable the capture of important tacit knowledge. Petrick and Provance (2005) state that the issue with tacit knowledge is converting it into a usable form. With content being populated across the canvas of the template, it provides a means to share "representations of information need" (Hansen and Järvelin, 2005). In this regard the template has been developed to act as a boundary object, and the knowledge captured through the schema is in a meaningfully structured format that can assist in establishing a shared understanding (Peng and Sutanto, 2012). Then the output of the template can be used to initiate and guide the technology intelligence activity, as it:

- Provides directive search queries.

- Defines information needs.

- Contrasts different information types.

- Highlights internal leveraging opportunities.

- Sets an initial 'watch list'.

- Points to potential contacts/collaborations.

\subsection{Mapping application areas}

The natural starting point for using the template is to agree and state the specific technology or technological domain. This is shown as Step 1a in Figure 3. It initiates the setting of the scope for defining the information needs. Within this initial scope setting section of the template, there also needs to be a mapping which attempts to relate the technology to potential application areas - Step $1 \mathrm{~b}$ in Figure 3. These two steps (1a and $1 \mathrm{~b}$ ) provide a context for the other parts of the template, which then are designed to support the definition of information needs relating to the specific technology.

The mapping of application areas offers an opportunity for managers/engineers/ scientists to discuss and capture the 'intent' for the technology and even provides a proxy for potential 'usefulness' across the business. As emphasized by Mietzner and Reger (2009), there must be "a link to operative business activities and value creation". Thus, this mapping of application areas makes the connection between the technology and potential internal uses for that specific technology by the company. Additionally, from an organizational learning perspective, the mapping also addresses such issues as 'departmentalization' (Levinthal and March, 1993) as it can be used to highlight potential future interactions between different business groups in regards to a given technology or technological domain. A key aspect of this section of the template is 'relevance'. Tushman and Scanlan (1981) note that acquiring timely information is important but it is also important that such information "be translated so that it is of relevance to the organization". So, by the upfront mapping of the technology to application areas across the business, it serves as a mechanism to identify potential internal 'customers' (i.e. intended users of the technology). 


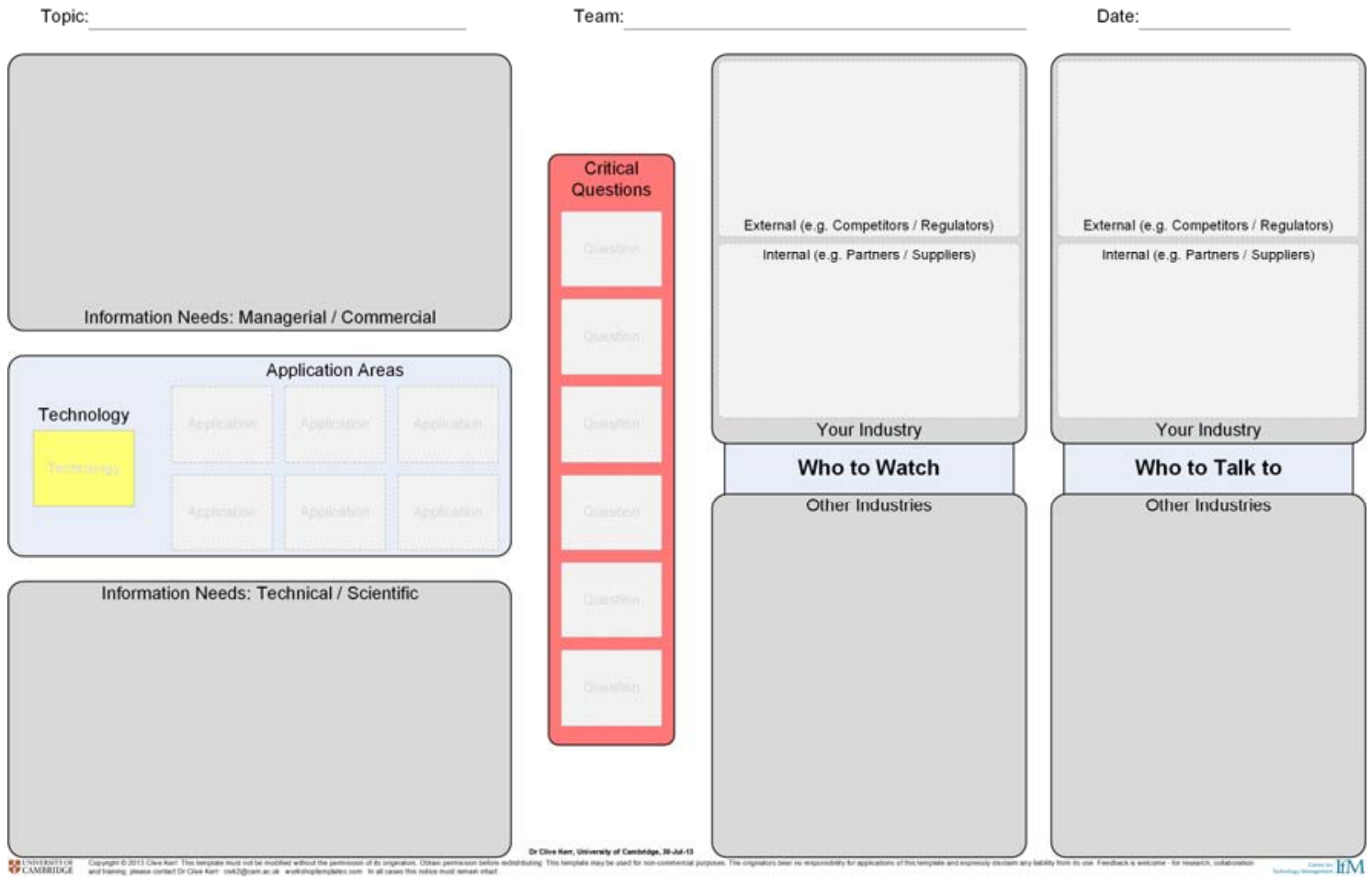

Fig. 1. Technology intelligence 'information needs' template.

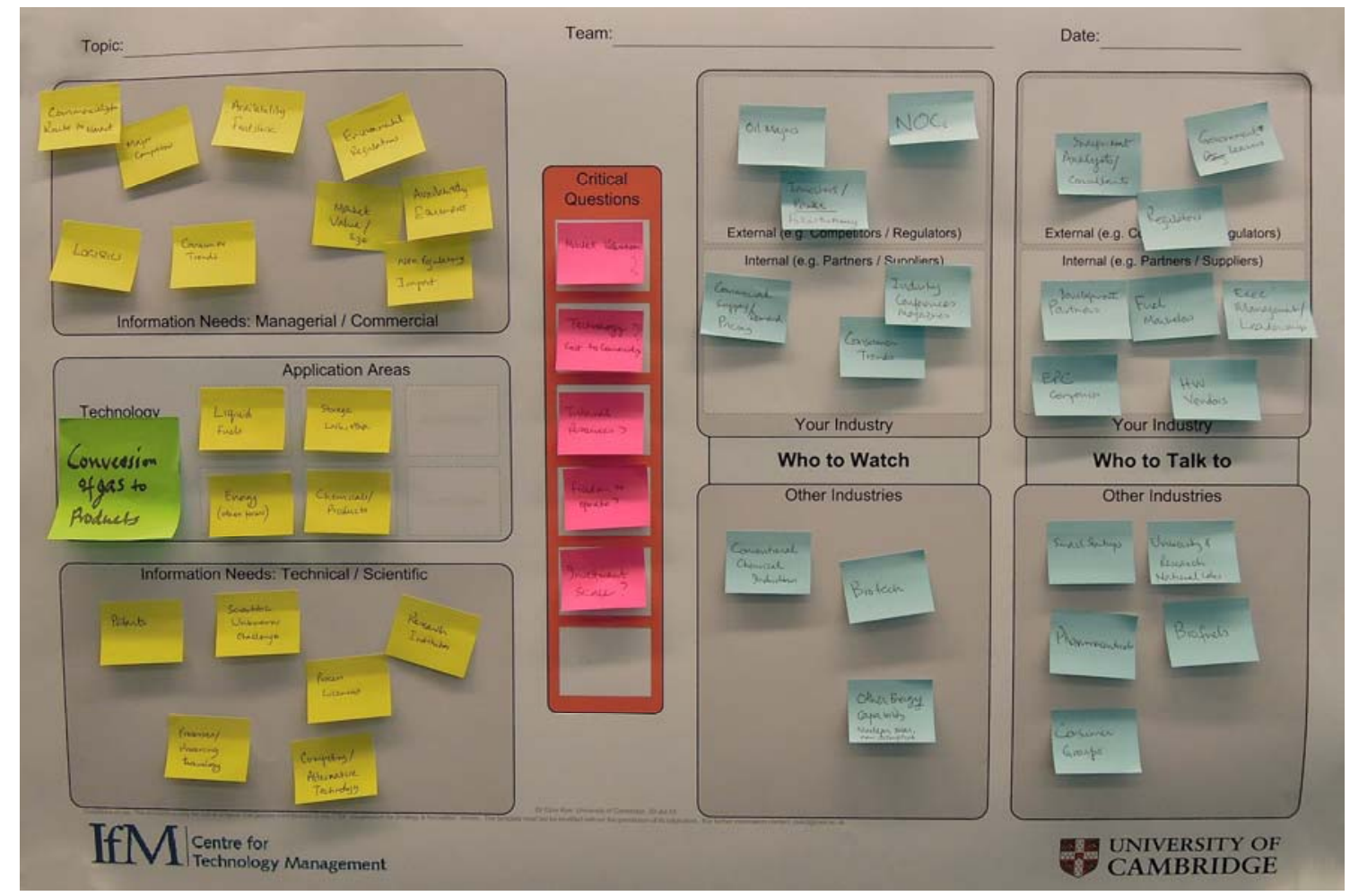

Fig. 2. Example of the template populated with content. 


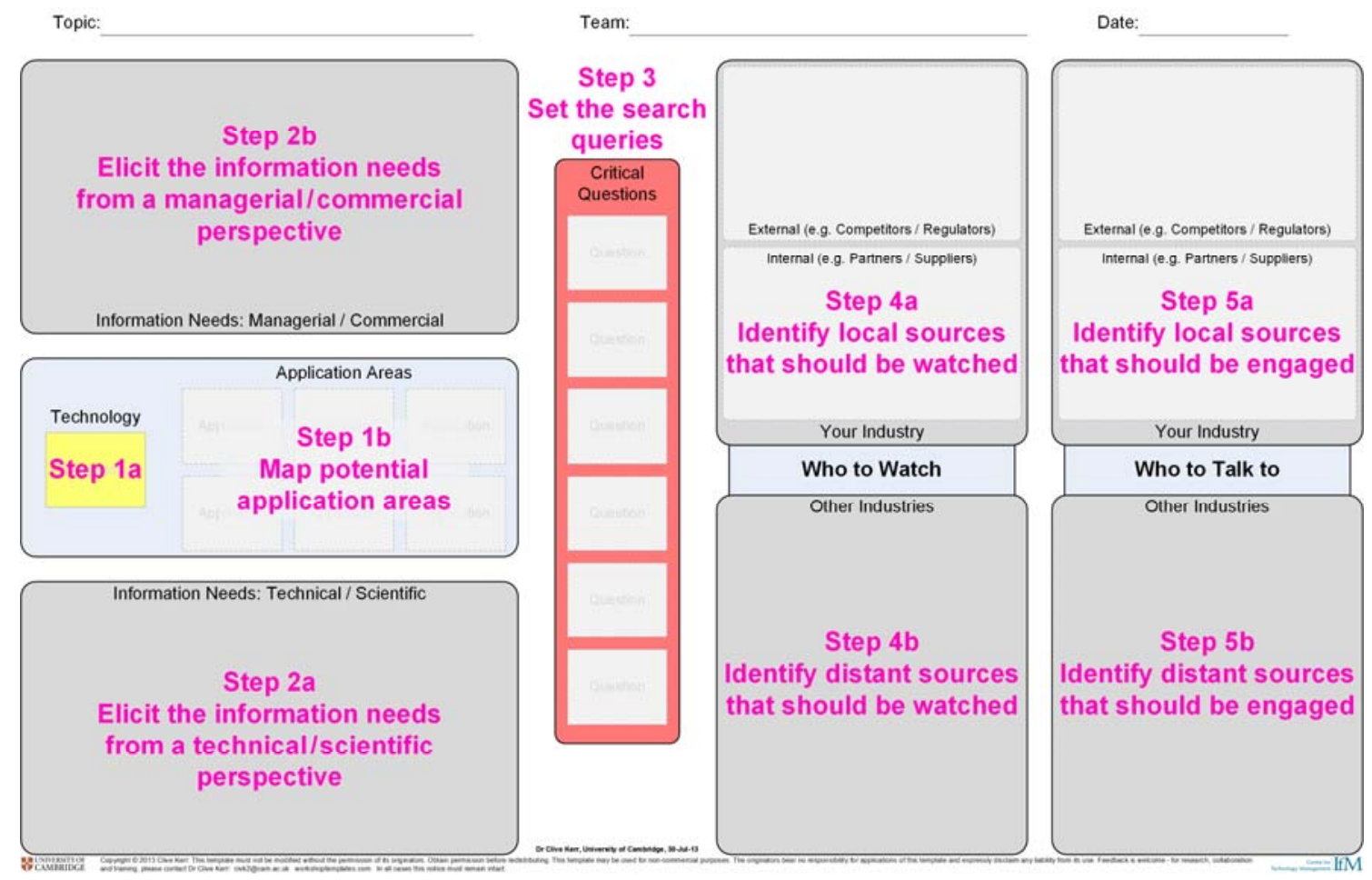

Fig. 3. Steps for completing the template.

\subsection{Eliciting information needs}

It must be ensured that any information disseminated/communicated by the technology intelligence activity is 'useful' for the intended recipients. Once the scope has been set, the next phase of using the template is an in-depth elicitation of the actual information needs relating to the specific technology (or technological domain). This is the main component of the specification/definition of information needs - depicted in Figure 3 as Step $2 \mathrm{a}$ and Step $2 \mathrm{~b}$. It is driven by the following question: what information needs to be gathered/collected? It is, in essence, an exploration of the 'search' parameter space to identify and highlight corporate knowledge gaps in relation to the specific technology or technological domain (given in Step 1).

As highlighted previously, the aim of using the template in a workshop/small-group environment is to facilitate and support the collaborative definition of information needs. The collaborative definition by a small group of interdisciplinary/multifunctional participants is important. As the participants brainstorm, capture information needs on sticky notes and start populating this section of the template, there should be discussions taking place beyond simple points of clarification. The activity of using the template to share different points of view should both enable and enrichen discussions about the array of opinions and patterns of variation in regards to: what constitutes appropriate/relevant information for the intended audience/recipients? Given that potential application areas have been identified in Step $1 \mathrm{~b}$, which points to internal 'customers/users' for the technology, it is helpful if participants also have a discussion as to their beliefs about the significance of the information being sought and how it might be interpreted and considered 'useful'. 
As information needs are identified and discussed by the participants, these are populated onto Steps $2 \mathrm{a} / 2 \mathrm{~b}$ of the template (Figure 3 ). This is used to differentiate the technological/scientific issues from commercial/market-related aspects and provides a clear contrast between two very distinct information types. Steps $2 \mathrm{a} / 2 \mathrm{~b}$ are conducted in parallel as participants put the appropriate sticky notes in the relevant part of the template - as can be seen in the example of Figure 2. Once the individual inputs have been captured and consolidated onto the template, the next step is to use these insights to set the search queries. But before moving onto the next step, it must be acknowledged that this phase of using the template is equivalent in function to the Key Intelligence Topics (KITs) from Competitive Intelligence (Herring, 1999). KITs are used to provide purpose for the subsequent intelligence activities (Bose, 2008; Francis and Herring, 1999). However, it must be highlighted that KITs tend to be fairly broadbased and so they should be made more tangible and granular by expressing them into specific KIQs (Key Intelligence Questions) that need to be explicitly 'answered' (Bartes, 2014; Herring, 2006; Weiss, 2002). To clarify: KITs are represented in Steps $2 \mathrm{a} / 2 \mathrm{~b}$ of the 'information needs' template and these are then expressed as KIQs in Step 3 (outlined in the next section).

\subsection{Setting the search through directive questions}

From Citroen's (2011) research on the role of information in strategic decisionmaking, asking the right questions and being aware of what information may still be missing is key in attempting to reduce executive uncertainty. That means the information captured in Steps $2 \mathrm{a} / 2 \mathrm{~b}$ must be challenged and reflected upon by the participants in order to check for missing elements. Then comes the stage of 'query formulation' (Hansen and Järvelin, 2005). Participants are asked to formulate and articulate a set of leading/critical questions that will be used to direct the technology intelligence activity. Step 3 of the template is essentially a co-creation of directive search queries'. This is a crucial step and the most important aspect is that the questions must be meaningful. These can range from fundamental questions such as:

- Who represents the current state-of-the-art? And to date, what have they been able to demonstrate?

- How rapidly is the technology progressing? What are the underlying factors/ influences driving this progression?

- What are the most problematic technological challenges being faced? Which technological issue represents the greatest development hurdle?

- How scalable is this technology? Who is expressing interest in potential applications and exploring uses?

To more specific queries that represent concerns/worries to internal stakeholders, such as:

- What technical capabilities and resources are needed to take a leadership position in this domain? What are the implications of being a follower and consequences on our current product lines?

- When is it likely for this technology to be economically feasible for us to consider fielding in our products?

- How much initial seed funding is necessary to learn and demonstrate that the technology has potential to provide competitive differentiation? 


\subsection{Identifying internal and external knowledge sources}

By leveraging the knowledge of the participants and tapping into their social networks, the remaining parts of the template are focused on eliciting and identifying potentially helpful sources and contacts that can then be approached when addressing the search queries (developed in Step 3). Fundamentally, the identification of sources is orientated to answering the question: "where am I going to find what I want to know?" (Myburgh, 2004). The sources captured on the template represent prospective channels for the technology intelligence activity by pointing to collaborations/relationships/contacts. Additionally, there is also a form of 'source selection' (Hansen and Järvelin, 2005) taking place as participants are making judgments about relevance and importance as they populate the template with fruitful sources in respect of the directive questions.

Steps 4 and 5 are based on the dimension of 'knowing who' (Powell and Swart, 2005). As can be seen in Figure 3, it is obviously split into two parts: considering initially 'who to watch' (Step 4) and then 'who to talk to' (Step 5). This contrast allows for a distinction to be clearly made between the differing technology intelligence mechanisms that could be deployed against the 'watching' and 'talking' activities. 'Watching' embodies activities such as technology monitoring (i.e. "maintaining updated information on the state-of-the-art, trends and forecasts") and benchmarking, e.g. tracking development initiatives (Nosella et al., 2008). Whereas 'talking' activities are active engagements involving extensive fieldwork; for example, through innovation/technology scouting (Nosella et al., 2008; Rohrbeck, 2010).

Karunakaran et al. (2013) acknowledge that information is "fragmented across multiple actors, artifacts, and systems". Therefore, Steps 4 and 5 are also split into components based on the dimension of distance, i.e. local versus distant (Kerr et al., 2006; Lin and Li, 2013; Miller et al., 2007). The concept of local refers to internally within the organization and its respective supply chain, and the wider external spectrum of actors/agents within the organization's own industry. As such, Steps 4a/5a are labeled 'Your Industry' and have sections for 'Internal' (organizational perspective) and 'External' (industry perspective). In regards to organizational sources, participants are prompted to highlight internal leveraging opportunities (taking into account the extent of firm divisionalization and spread of knowledge repositories/systems) so enabling the mining and trawling of existing information (Kerr et al., 2006). The definition of internal encapsulates the organizational value/supply chain, with the need to leverage these sources of intelligence as highlighted by a study by Chiu (2014) which found that supplier diversity stimulates more exploration of novel technologies. Furthermore, external sources (i.e. beyond organizational boundaries but still within the same industry) are used to broaden the type of information that can be made available. Such a boundary-spanning search approach has been categorized by Lin and Li (2013) as 'spatial-side' search and includes competitor-driven intelligence and, depending on the industry, other sources such as regulators and advisory/standards bodies. Steps $4 \mathrm{a} / 5 \mathrm{a}$ are limited to organizational boundaries within the specific industry, in contrast Steps $4 b / 5 b$ expand the search to 'Other Industries' (i.e. distant sources). Very crucially, Steps $4 b / 5 b$ are used to open the exploratory search across supply-side technological boundaries (Laursen, 2012; Lin and Li, 2013; Sidhu et al., 2007). According to Sidhu et al. (2007), this encompasses: 
- All industries that employ the sort of technology that our organization uses.

- Industries that are technologically related to ours.

- Companies not active in our product area, but that have skills and know-how comparable to ours.

As participants are populating the template with potential sources (Steps 4a-4b-5a$5 b$ ), they must be cognizant that formal and informal social networks can provide powerful channels. From an internal/local perspective, certain executives and researchers are often well known for having access to broad and/or deep connections the names of such individuals should be captured on the template. Citroen (2011) emphasizes that information arrived 'bottom up' through the organization is generally trusted more than information directly provided by external sources. Middle managers can act as important sources due to their bridging and brokerage roles for acquiring diffuse information across different hierarchical levels (Shi et al., 2009). Some managers become focal points in networks as they act as gatekeepers who can facilitate and supply information across boundaries (Mietzner and Reger, 2009; Shi et al., 2009). Lin and $\mathrm{Li}$ (2013) stress the need to go beyond the existing knowledge space and in that regards it is prudent to consider third-party intermediaries who can readily facilitate access to distant knowledge (Agogué et al., 2013). They are often critical structural/social nodes to much larger networks (Landry et al., 2013) and who can proactively mediate/ease the flow of information (Gould and Fernandez, 1989) through scanning, processing (combination/recombination) and brokering (Howells, 2006).

\section{Modes of deployment}

Underpinning the use of the template, as a tool, is the principle that it must enable and support users to participate/engage/collaborate with one another so as to have useful/meaningful discussions and produce agreed co-created outputs (Kerr et al., 2013). The recommended approach for using the template is through workshops (this includes working meetings and small group activities as part of team meetings) as they provide an environment for interaction and mutual exploration (when appropriately facilitated). It is also recognized that workshop-based interactions might become increasingly distributed and virtual in the future via digital means.

With a workshop approach, there are two modes for deploying the template. First, and most obvious, is to deploy the template as an independent and self-contained activity with a small group, or number of groups, convened for the sole purpose of identifying and capturing the information needs relating to a given technology or technological domain, so priming/directing the technology intelligence. The second mode of deployment is integrated with other management/planning tools as part of an overarching structured process for technology strategy. This would then ensure that its application is tailored for the organization's strategic planning method and is better interlinked with the relevant decision-making mechanisms (Mietzner and Reger, 2009).

In regards to other potential management tools, Kerr et al. (2006) have already pointed to the integration of technology intelligence with roadmapping. Within the field of technology and innovation management, roadmapping is recognized as a prominent and popular tool - this is based on its ability to "provide a graphic representation which can be used to explore and to communicate the relationships between markets, products, and technologies over time" (Geum et al., 2013). More specifically in regards to 
technology intelligence, roadmapping enables the identification of technology and research gaps (Gindy et al., 2006; Vatananan and Gerdsri, 2012).

Kerr et al. (2006) formalized the conceptual interaction between roadmapping and technology intelligence based on the collection and delivery of information guided by emergent themes ('what do we know' vs 'what do we need to know') and white spaces ('what do we not know' vs 'what do we need to know') on the canvas of the roadmap during its initial population with content. This has been built upon to generate three procedural options for integrating the roadmapping tool with the technology intelligence 'information needs' template. Taking the S-Plan roadmapping approach (Phaal et al., 2007) as an exemplar reference process, since it is well established and used by numerous organizations, the three procedural options are depicted in Figure 4, namely:

- A 'hotspot' or 'theme' on the roadmapping landscape.

- A 'gap' or 'white space' on the roadmapping landscape.

- A specific 'topic' from an exploratory/opportunity roadmap.

The first two of these options, which can be conducted in parallel, are based off a roadmapping landscape. In S-Plan, a strategic landscape is initially generated in order to "share and capture as many perspectives as possible across the full scope of the area of interest" (Phaal et al., 2007). Thus, the landscape not only provides a context for an area/field, it acts as a foundational information resource since participant-driven content (in the form of views/opinions/impressions/interests) is populated across its structured canvas. By interrogating the landscape, there may be clearly identifiable and recognized technologies (i.e. a series of individual 'hotspots') which require more information to be sought by the organization in order to better understand their significance and potential utility - hence a direct input into the 'information needs' template as shown in Figure 4. Additionally, across the landscape, there may be apparent clusters which either consist of a number of related technologies and/or a distinct set of latent/emergent technological 'themes' around a given application. 'Hotspots' and 'themes' are explicitly generated from content on the landscape. Conversely, upon reflection of the overall landscape and individual layer/sub-layers, the absence or lack of populated content is implicitly a potential indicator for the need to employ technology intelligence. The term 'implicitly' has been used in this instance as, generally, organizations overlook or fail to appreciate what's missing because they are strongly attracted to the 'hotspots' (these are often immediately seen as the priority). There may be regions with little, if any, content (i.e. 'white spaces') and upon inspection some of these may be deemed to be areas where the organization is deficient in its scanning for potential technologies. Furthermore, due to recognized and acknowledged gaps in organizational knowledge, there will be sparsely populated areas which should actually be coherent clusters - again, these can be fed through to the 'information needs' template.

The third and final procedural option for formally linking the tools is through the prioritization and selection of topics (Figure 4). Following the landscaping activity, a set of strategic opportunities are explored in more depth to produce 'first-cut' roadmaps (Phaal et al., 2007) - these are often called 'topic' maps (i.e. key landmarks from the landscape). As participants are developing possible routes forward, there will be instances where the technological dynamics (drivers, trends, etc.) and associated profiling (emergence, divergence, etc.) are not well known. Those topics can then be used as the reference point for Step 1a of the template (Figure 3). 


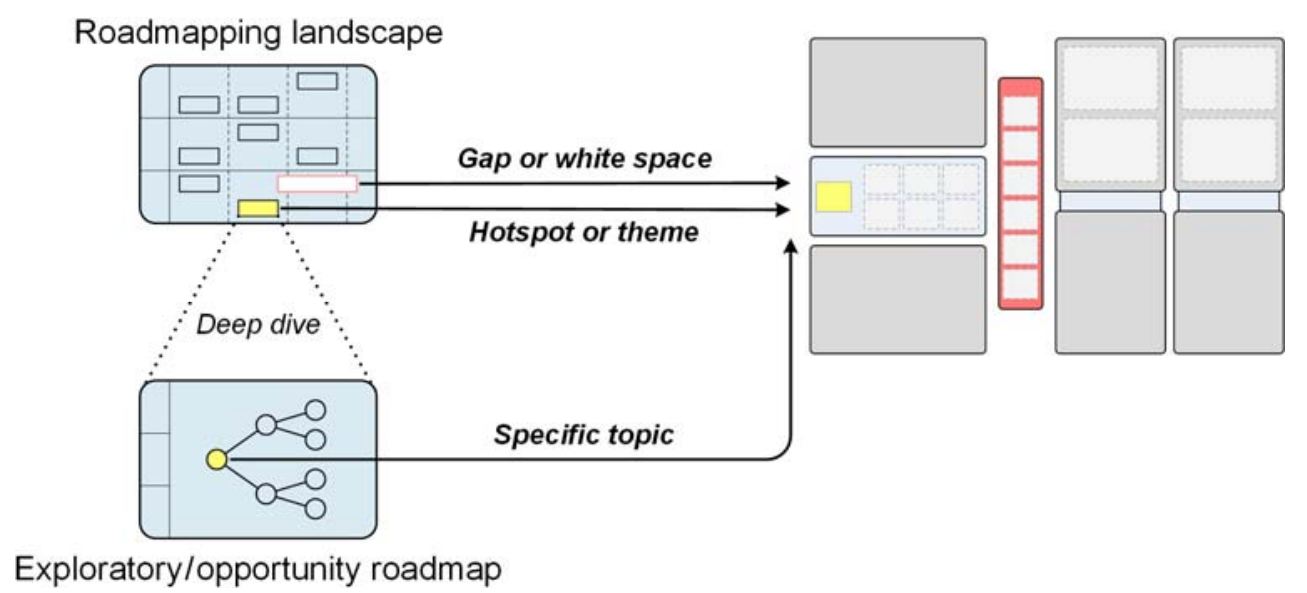

Fig. 4. Inputs from roadmapping.

\section{Field testing the template}

Having developed the 'information needs' template (underpinned by the relevant theory), designed its visual layout and considered the process aspects for its application, there was an opportunity to pilot its use with a multinational energy company. As part of a 3-day executive training program in technology and innovation management, the template was able to be tested in a realistic environment with industrial practitioners and with actual organizational-relevant challenges. Additionally, roadmapping was a major element of the program and so the integration between the two tools could also be piloted in an exploratory manner. It must be emphasized that although the testing provided a representative field case, the scope was limited to:

- Trialing the 'information needs' template - participant interaction and population with content.

- Piloting the procedural link between the roadmapping landscape and the 'information needs' template - the generation of hotspots/themes and the identification of gaps/white spaces to feed into the template.

Excluded from the field testing was the interplay and feedback cycle from the technology intelligence operatives - this is scope for future work (which is required to fully validate any implementation).

The participants were a mixed group of managers (both commercial and technical) and engineers/scientists from across the organization -14 people in total. The mix of participants admitted to the program was balanced by the organization, as they wanted to ensure the exchange of experiences/lessons/knowledge and to provide a platform for networking/sharing beyond the training into practice. All the participants took part as a large group to conduct the roadmapping landscape activity, which was generated through brainstorming guided by the following structure:

- Trends and drivers - political, economic, social, technological, legal and environmental.

- Customers - external (wholesale, retail) and internal (assets, regions).

- Principal actors - segments, business units, strategic partners and competitors.

- Applications - discovery, recovery, operations, efficiency. 
- Technology - downstream (conversion, refining, etc.) and upstream (seismic, wells, etc.).

- Resources - skills, systems, infrastructure, etc.

The landscape produced can be seen in Figure 5, i.e. the large wallchart on the righthand side of the photograph (for reference: the central chart in the photograph is the 'information needs' template).

Following the landscape activity and an introduction to technology intelligence, participants were formed into four small multifunctional groups (consisting of 3-4 people). The groups were directed to look over the landscape, make themselves aware of any hotspots/themes/gaps/white spaces, have a discussion on which of those would be appropriate for the group given its composition, and to then make a selection for transfer over to the 'information needs' template. The template was printed as A1-sized posters. Each group, working in parallel, was tasked with completing the template by following the five steps and instructed to capture their discussion/insights/ recommendations onto sticky notes so as to populate the relevant sections (Figure 6). The activity was then closed by each of the groups summarizing their content and feeding back their main observations/learning points to the other groups as part of an overall plenary discussion and activity review. Since the field testing of the template involved real content on strategic concerns facing an actual organization, the findings/outcomes reported in this paper have been summarized by looking across the groups for generalized and recurring issues, and drawing out the pertinent observations. In describing the content generated by the groups, certain details and specifics that are commercially sensitive have been omitted.

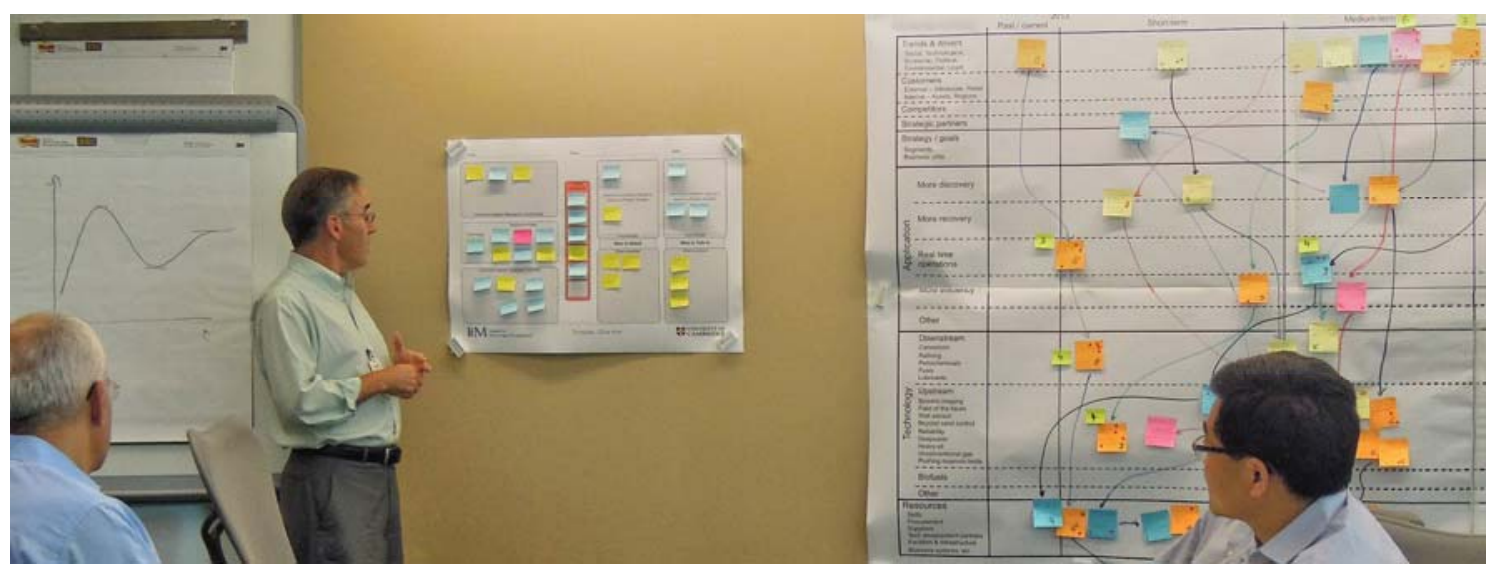

Fig. 5. Field testing the template. 

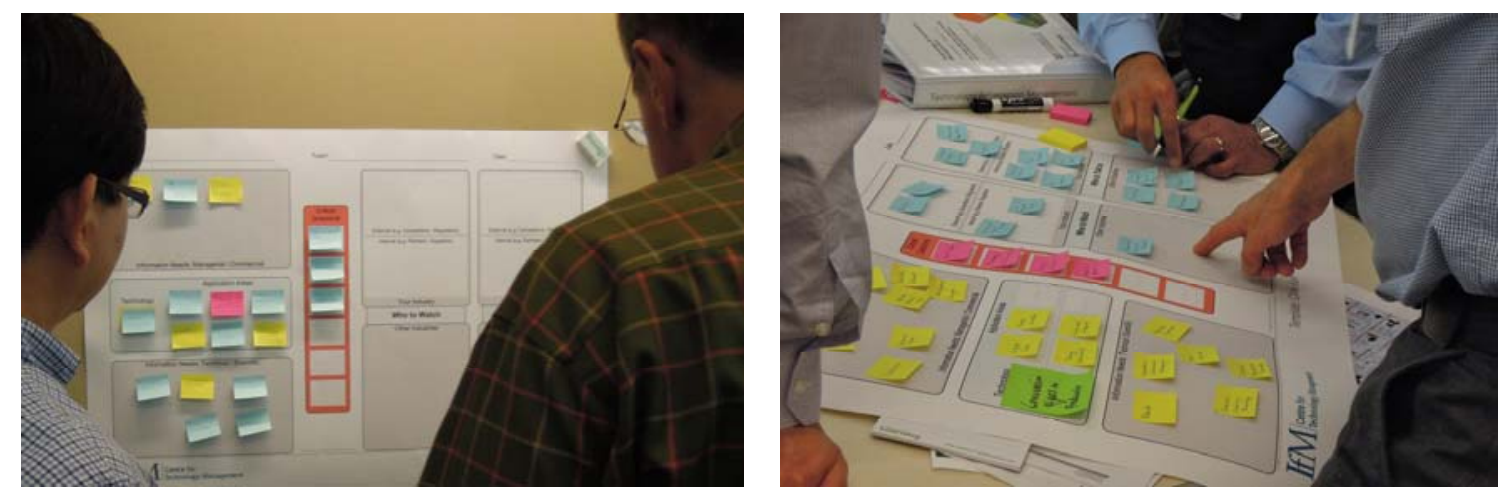

Fig. 6. Groups using the template.

The procedural link between the roadmapping landscape over to the information needs' template had a natural flow, although there was one apparent weakness - i.e. the recognition of white spaces. Using the landscape as the basis for input, the selection of specific technologies or technological domains by the four groups were:

- 3D printing.

- Composite materials for risers.

- Real-time corrosion monitoring.

- Conversion of gas to products.

For the organization, these topics represented hotpots (e.g. 3D printing), themes (e.g. real-time corrosion monitoring) and recognized gaps (e.g. composite materials for risers). None of the selected topics were white spaces. It is important to acknowledge that there is potentially a heavy cognitive load associated with traversing and interrogating a landscape. General observations from this part of the field testing were:

- Hotspots are easily recognized and tend to draw most attention.

- Clusters of sticky notes can be readily identified and attributed as specific themes (using an appropriate protocol in the landscaping activity).

- The recognition of gaps appears to be elevated and brought to the wider group attention by specific individuals, such as technical experts, hence the importance of ensuring appropriate participants are invited to take part.

- Just being explicitly aware of white space is an easily overlooked element for participants and, if noticed, the recognition of its significance appears to be problematic.

The amount and regions of physical white space on the roadmapping landscape chart is obviously very visible, but the conceptual translation that a specific lack of content in a region of the chart manifests a discernable lack of knowledge is a challenge when reviewing the landscape. For white spaces, there needs to be more granular resolution as to their significance. The lack of an appropriate set of lenses for 'sense-making' is a significant constraint. Although the roadmapping landscape is structured (via layers/sub-layers and an explicit time axis), the coverage of the canvas is fairly 'freeform' and the implied insights from the landscape can vary widely in terms of substance, relevance and clarity. So, there needs to be a systematic analysis and critical reflection of the landscape. One way to achieve this is through a 'situational analysis schema' consisting of a number of key conceptual building blocks/categories, and underlying data classes, which in combination provide potential lenses for interrogating a roadmapping landscape. It would in effect provide a systematic checklist and robust 
protocol to support the identification of significant 'signals' from the landscape and help deduce their meaning/implications for the organization. This is currently the subject of an ongoing research project that will be reported on in the near future. In the longer-term, such a 'situational analysis schema' could provide a potential mechanism for auditing a populated landscape and might even act more widely as a means of benchmarking outputs from roadmapping processes.

Making the distinction between the information needs from the technical/scientific versus managerial/commercial perspectives (Steps $2 \mathrm{a} / 2 \mathrm{~b}$ ) proved very helpful for the participants as it provided a means of better eliciting and classifying the types of information in a relevant and specific manner. For example, comparing across the four groups, the information needs from the technical/scientific perspective were very tangible and took the form of:

- Profiling and trending - technology maturity levels and direction of development (e.g. new functionalities) and their nature (i.e. pivot points, step changes).

- Performance indicators - leading measures and their pace, threshold levels (i.e. where it gets interesting from a system/product view).

- Utility - scope of application and the nature of its scalability.

- Concerns/risks - underlying factors such as reliability, industry standards and potential barriers.

- Capabilities - implications for internal know-how (e.g. leverage, build, develop) and the organization's ability to respond.

Similarly, from the managerial/commercial perspective, very tangible and distinct types of information were being sought:

- Classic financials - market size/value, scale of investment required, cost-benefit.

- Customer-focused/pull - value proposition and customer benefits, impact and evolution of the business model, commercialization routes, cannibalization of the current product range.

- Competitive dynamics - freedom to operate, nature of differentiation, market reactions, competitor investments and associated relationships.

In regards to the co-creation of directive search queries, the feedback for this part of the template (Step 3) highlighted it as the most critical element, which of course is the design intent since its sets the 'exam questions' for the technology intelligence activities to answer. The observation across the groups was that it reinforces the need for clarity and conciseness in articulating both understandable and meaningful requests for information. Upon reviewing the individual sets of questions generated by each group, a number of question types were emergent (please note that the wording/phrasing of the exemplar questions below have been edited/generalized to avoid commercially sensitive details):

- Proactive versus reactive (e.g. For this specific technology, what are the implications of 'innovate vs wait' strategies? What advantages are available for investing 'early vs late'?).

- Practicalities (e.g. What could we demonstrate in the short-term? How do we compare to the state-of-the-art? How behind are we compared to our competitors?).

- Knock-on effects (e.g. What is the likely impact on our technology portfolio? For this specific technology, what is our current level of technical understanding and 
what is needed to develop internal capabilities? Would those be central or distributed capabilities?).

- Relationships (e.g. Who might be potential partners? What are the options for 'make vs buy'? Are there research initiatives that we should consider joining? What are the licensing opportunities?).

This is an interesting area for future research: by deploying the template a sufficient number of times across a representative set of organizations, it may be possible to generate an initial classification of generalizable question types.

For the parts of the template which involved identifying internal and external knowledge sources in terms of 'who to watch' and 'who to talk to' (Steps 4a-4b-5a-5b), each group had their own specific named sources relevant for their given technology/technological domain. However, looking across the groups and generalizing the potential sources, a basic typology was evident. This typology of sources ranged from the very obvious and popular sources, through to neighboring and similar industries, and then reaching out to more distant sources (where the applications/products are unrelated but the underpinning science is potentially common). The observed typology of sources was as follows:

- Obvious/popular (e.g. universities, patents).

- Overlapping/associated domains (e.g. offshore, marine).

- Other energy sectors (e.g. nuclear, solar).

- Similar/neighboring industries (e.g. conventional chemical).

- Classic fields of engineering (e.g. aerospace, automotive).

- Perceived cutting-edge science (e.g. biotech, pharma, medical).

Each group managed to identify a spread of sources that spanned most of those different categories. But it must be noted that the local/closer sources were clearly pinpointed (e.g. speak to person $\mathrm{X}$ or watch company $\mathrm{Y}$ ) whereas the more distant sources were expressed much more vaguely (e.g. connecting with the biotech field might stimulate/provoke a new angle on this technical problem). Of course, the typology is only an observation from an individual case, but it has the potential to serve as a useful checklist of sources should the organization decide to apply the 'information needs' template to other instances. Jumping to potential future applications of the template, if it were to be rolled out to the organization beyond the piloting stage and subject to further refinements based on user feedback, the canvas of the template for Steps $4 a-4 b-5 a-5 b$ could be segmented into a number of placeholders for potential sources based on the typology.

From the closing plenary discussion and activity review, two open questions were put forward by the participants:

- How much focus should there be on competing/alternative technologies?

- What constitutes 'actionable' intelligence for a 'go versus no-go' decision?

It is hoped that by sharing these two potential research questions, there may be some insights and advice forthcoming from the technology intelligence and technology management communities.

\section{Summary}

In considering how to provide an explicit and formalized link from strategic planning to technology intelligence, it was observed that there was a lack of theoretically- 
grounded and pragmatic tools to support the scoping of 'information needs' from key stakeholders (e.g. decision-makers). For technology intelligence to be effective, it has to be primed with a clear and meaningful input from strategy in order to direct the subsequent search processes. As a precursor to the actual seeking and exploring for potentially useful information/knowledge, there should first be a phase that elicits the type of information required and bounds the search space. To ensure that such an input is meaningful and relevant, a representative set of stakeholders should collaboratively articulate and agree the search queries/questions. It is within this context that a template-based tool was developed to both address the research gap and to offer a practical means for industry to specify 'information needs' and then guide/direct the subsequent technology intelligence activities.

The 'information needs' template is structured in a step-wise fashion and comprised of the following parts:

- Map the application areas - relate the technology/technological domain to potential internal 'customers' across the organization.

- Elicit information needs - determine what constitutes appropriate/relevant information for the intended recipients, and differentiate the technological/ scientific issues with the commercial/market-related aspects.

- Set the directive search queries - translate the information needs into a number of meaningfully articulated questions to direct the subsequent technology intelligence activities.

- Identify who to watch - recognize and capture potential internal and external knowledge sources in terms of the organizational/supply chain view and crossindustry perspectives.

- Identify who to talk to - recognize and capture potential internal and external sources of knowledge who should be actively contacted (potentially leading to fieldwork activities, mutual engagements or even collaborations).

The template can be coupled with roadmapping, with a roadmapping landscape providing a platform for recognizing hotspots/themes/gaps/white spaces, serving as an input to the template. Such an integration between the two tools establishes a coherent link between strategic planning and technology intelligence.

The template was field tested using real technological-relevant challenges facing a specific organization. Four parallel groups of industrial practitioners used the template as a workshop activity within a technology intelligence module of an executive training program. This acted as an exploratory pilot. The feedback on using the template, and the content it captured, was positive. One identified area of weakness was the problematic nature of recognizing and appreciating the significance of white spaces this is an area that requires more attention and future research. From the initial field test, a basic typology of potential sources was evident. This means that the canvas of the template can be tailored and refined for the organization by adding specific prompts/placeholders into the 'who to watch' and 'who to talk to' sections as defined by the typology (therein acting as a checklist of sources). It is hoped that through creating the 'information needs' template, and with providing the illustrative example of its use, it helps organizations to better direct and prime their technology intelligence. 


\section{References}

Agogué, M.; Yström, A. \& Le Masson, P. (2013) Rethinking the role of intermediaries as an architect of collective exploration and creation of knowledge in open innovation. International Journal of Innovation Management, 17 (20), 1350007 (24pp).

Arman, H. \& Foden, J. (2010) Combining methods in the technology intelligence process: Application in an aerospace manufacturing firm. R\&D Management 40 (2), pp. 181-194.

Aspinall, Y. (2011) Competitive intelligence in the biopharmaceutical industry: The key elements. Business Information Review, 28 (2), pp. 101-104.

Bartes, F. (2014) The objectives of competitive intelligence as a part of corporative development strategy. Acta Universitatis Agriculturae et Silviculturae Mendelianae Brunensis, 62 (6), pp. 1243-1250.

Bose, R. (2008) Competitive intelligence process and tools for intelligence analysis. Industrial Management \& Data Systems, 108 (4), pp. 510-528.

Brodbeck, F. C.; Kerschreiter, R.; Moizisch, A. \& Schulz-Hardt, S. (2007) Group decision making under conditions of distributed knowledge: The information asymmetries model. Academy of Management Review, 32 (2), pp. 459-479.

Carlile, P. R. (2002) A pragmatic view of knowledge and boundaries: Boundary objects in new product development. Organization Science, 13 (4), pp. 442-455.

Chiu, Y. C. (2014) Balancing exploration and exploitation in supply chain portfolios. IEEE Transactions on Engineering Management, 61 (1), pp. 18-27.

Citroen, C. L. (2011) The role of information in strategic decision-making. International Journal of Information Management, 31 (6), pp. 493-501.

Clayton, C.; Lin, A. \& Pitt, J. (2011) Key intelligence topics and key intelligence questions in safety signal intelligence. Proceedings of the 14th International Conference on Information Fusion, 5-8 July 2011, Chicago, USA.

Dervin, B. (1998) Sense-making theory and practice: An overview of user interests in knowledge seeking and use. Journal of Knowledge Management, 2 (2), pp. 36-46.

Ettorre, B. (1995) Managing competitive intelligence. Management Review, 84 (10), pp. 15-19.

Fenton, E. M. (2007) Visualising strategic change: The role and impact of process maps as boundary objects in reorganisation. European Management Journal, 25 (2), pp. 104-117.

Francis, D.B. \& Herring, J.P. (1999) Key intelligence topics: A window on the corporate competitive psyche. Competitive Intelligence Review, 10 (4), pp. 10-19.

Geum, Y.; Kim, J.; Son, C. \& Park, Y. (2013) Development of dual technology roadmap for open innovation: Structure and typology. Journal of Engineering and Technology Management, 30 (3), pp. 309-325.

Gindy, N. N. Z.; Cerit, B. \& Hodgson, A. (2006) Technology roadmapping for the next generation manufacturing enterprise. Journal of Manufacturing Technology Management, 17 (4), pp. 404-416.

Golovatchev, J.; Budde, O. \& Kellmereit, D. (2010) Technology and Innovation radars: Effective instruments for the development of a sustainable innovation strategy and successful product launches. International Journal of Innovation and Technology Management, 7 (3), pp. 229-236. 
Gould, R. V. \& Fernandez, R. M. (1989) Structures of mediation: A formal approach to brokerage in transaction networks. Sociological Methodology, 19, pp. 89-126.

Hansen, P. \& Järvelin, K. (2005) Collaborative information retrieval in an informationintensive domain. Information Processing \& Management, 41 (5), pp. 1101-1119.

Herring, J.P. (1999) Key intelligence topics: A process to identify and define intelligence needs. Competitive Intelligence Review, 10 (2), pp. 4-14.

Herring, J.P. (2006) KITS revisited: Their use and problems. Competitive Intelligence Magazine, 9 (5), pp. 12-14.

Howells, J. (2006) Intermediation and the role of intermediaries in innovation. Research Policy, 35 (5), pp. 715-728.

Jarzabkowski, P.; Balogun, J. \& Seidl, D. (2007) Strategizing: The challenges of a practice perspective. Human Relations, 60 (1), pp. 5-27.

Karunakaran, A.; Reddy, M. C. \& Spence, P. R. (2013) Toward a model of collaborative information behavior in organizations. Journal of the American Society for Information Science and Technology, 64 (12), pp. 2437-2451.

Katila, R. \& Ahuja, G. (2002) Something old, something new: A longitudinal study of search behavior and new product introduction. Academy of Management Journal, 45 (6), pp. 1183-1194.

Kerr, C. I. V.; Mortara, L.; Phaal, R. \& Probert, D. R. (2006) A conceptual model for technology intelligence. International Journal of Technology Intelligence and Planning, 2 (1), pp. 73-93.

Kerr, C.; Phaal, R. \& Probert, D. (2012) Cogitate, articulate, communicate: The psychosocial reality of technology roadmapping and roadmaps. R\&D Management, 42 (1), pp. 1-13.

Kerr, C.; Farrukh, C.; Phaal, R. \& Probert, D. (2013) Key principles for developing industrially relevant strategic technology management toolkits. Technological Forecasting and Social Change, 80 (6), pp. 1050-1070.

Landry, R.; Amara, N.; Cloutier, J. S. \& Halilem, N. (2013) Technology transfer organizations: Services and business models. Technovation, 33 (12), pp. 431-449.

Laursen, K. (2012) Keep searching and you'll find: What do we know about variety creation through firms' search activities for innovation? Industrial and Corporate Change, 21 (5), pp. 1181-1220.

Lee, S.; Mortara, L.; Kerr, C.; Phaal, R. \& Probert, D. (2011) Corporate document mining for technology intelligence: An analysis of needs, utilisation and possibilities. International Journal of Technology Intelligence and Planning, 7 (2), pp. 110-127.

Lee, S.; Mortara, L.; Kerr, C.; Phaal, R. \& Probert, D. (2012) Analysis of documentmining techniques and tools for technology intelligence: Discovering knowledge from technical documents. International Journal of Technology Management, 60 (12), pp. 130-156.

Levinthal, D. A. \& March, J. G. (1993) The myopia of learning. Strategic Management Journal, 14 (S2), pp. 95-112.

Lichtenthaler, E. (2003) Third generation management of technology intelligence processes. R\&D Management 33 (4), pp. 361-375.

Lichtenthaler, E. (2004a) Technological change and the technology intelligence process: A case study. Journal of Engineering and Technology Management, 21 (4), pp. 331-348.

Lichtenthaler, E. (2004b) Technology intelligence processes in leading European and North American multinationals. R\&D Management 34 (2), pp. 121-135. 
Lichtenthaler, E. (2007) Managing technology intelligence processes in situations of radical technological change. Technological Forecasting and Social Change, 74 (8), pp. 1109-1136.

Lin, C. J. \& Li, C. R. (2013) The effect of boundary-spanning search on breakthrough innovations of new technology ventures. Industry and Innovation, 20 (2), pp. 93-113.

Lozada, H. R. \& Calantone, R. J. (1996) Scanning behavior and environmental variation in the formulation of strategic responses to change. Journal of Business \& Industrial Marketing, 11 (1), pp. 17-41.

Nag, R. \& Gioia, D. A. (2012) From common to uncommon knowledge: Foundations of firm-specific use of knowledge as a resource. Academy of Management Journal, 55 (2), pp. 421-457.

Nosella, A.; Petroni, G. \& Salandra, R. (2008) Technological change and technology monitoring process: Evidence from four Italian case studies. Journal of Engineering and Technology Management, 25 (4), pp. 321-337.

March, J. G. (1991) Exploration and exploitation in organizational learning. Organization Science, 2 (1), pp. 71-87.

Mietzner, D. \& Reger, G. (2009) Practices of strategic foresight in biotech companies. International Journal of Innovation Management, 13 (2), pp. 273-294.

Miller, D. J.; Fern, M. J. \& Cardinal, L. B. (2007) The use of knowledge for technological innovation within diversified firms. Academy of Management Journal, 50 (2), pp. 308-326.

Mortara, L.; Kerr, C. I. V.; Phaal, R. \& Probert, D. R. (2009a) Technology intelligence practice in UK technology-based companies. International Journal of Technology Management, 48 (1), pp. 115-135.

Mortara, L.; Kerr, C. I. V.; Phaal, R. \& Probert, D. R. (2009b) A toolbox of elements to build technology intelligence systems. International Journal of Technology Management, 47 (4), pp. 322-345.

Mortara, L.; Thomson, R.; Moore, C.; Armara, K.; Kerr, C.; Phaal, R. \& Probert, D. (2010) Developing a technology intelligence strategy at Kodak European Research: Scan and target. Research-Technology Management, 53 (4), pp. 27-38.

Myburgh, S. (2004) Competitive intelligence: Bridging organizational boundaries. Information Management Journal, 38 (2), pp. 46-55.

Park, H.; Kim, K.; Choi, S. \& Yoon, J. (2013) A patent intelligence system for strategic technology planning. Expert Systems with Applications, 40 (7), pp. 2373-2390.

Peng, Y. \& Sutanto, J. (2012) Facilitating knowledge sharing through a boundary spanner. IEEE Transactions on Professional Communication, 55 (2), pp. 142-155.

Petrick, I. R. \& Provance, M. (2005) Roadmapping as a mitigator of uncertainty in strategic technology choice. International Journal of Technology Intelligence and Planning, 1 (2), pp. 171-184.

Phaal, R.; Farrukh, C. J. P. \& Probert D. R. (2007) Strategic roadmapping: A workshop approach for identifying and exploring strategic issues and opportunities. Engineering Management Journal, 19 (1), pp. 3-12.

Porter, A. L. (2005) QTIP: Quick technology intelligence processes. Technological Forecasting and Social Change, 72 (9), pp. 1070-1081.

Porter, A. L. \& Newman, N. C. (2011) Mining external R\&D. Technovation, 31 (4), pp. 171-176.

Powell, J. H. \& Swart, J. (2005) This is what the fuss is about: A systemic modelling for organisational knowing. Journal of Knowledge Management, 9 (2), pp. 45-58. 
Rohrbeck, R.; Heuer, J. \& Arnold, H. (2006) The technology radar: An instrument of technology intelligence and innovation strategy. IEEE International Conference on Management of Innovation and Technology, Singapore, June 21-23, 2006.

Rohrbeck, R. (2010) Harnessing a network of experts for competitive advantage: Technology scouting in the ICT industry. R\&D Management, 40 (2), pp. 169-180.

Savioz, P. \& Blum, M. (2002) Strategic forecast tool for SMEs: How the opportunity landscape interacts with business strategy to anticipate technological trends. Technovation, 22 (2), pp. 91-100.

Schuh, G.; Aghassi, S.; Orilski, S.; Schubert, J.; Bambach, M.; Freudenberg, R.; Hinke, C. \& Schiffer, M. (2011) Technology roadmapping for the production in high-wage countries. Production Engineering: Research and Development, 5 (4), pp. 463-473.

Shah, C. (2014) Collaborative information seeking. Journal of the Association for Information Science and Technology, 65 (2), pp. 215-236.

Shi, W.; Markoczy, L. \& Dess, G. G. (2009) The role of middle management in the strategy process: Group affiliation, structural holes, and tertius iungens. Journal of Management, 35 (6), pp. 1453-1480.

Sidhu, J. S.; Commandeur, H. R. \& Volberda, H. W. (2007) The multifaceted nature of exploration and exploitation: Value of supply, demand, and spatial search for innovation. Organization Science, 18 (1), pp. 20-38.

Spee, A. P. \& Jarzabkowski, P. (2009) Strategy tools as boundary objects. Strategic Organization, 7 (2) pp. 223-232.

Tushman, M. L. \& Scanlan, T. J. (1981) Boundary spanning individuals: Their role in information transfer and their antecedents. Academy of Management Journal, 24 (2), pp. 289-305.

Vatananan, R. S. \& Gerdsri, N. (2012) The current state of technology roadmapping research and practice. International Journal of Innovation and Technology Management, 9 (4), pp. 1250032 (1-20).

Veugelers, M.; Bury, J. \& Viaene, S. (2010) Linking technology intelligence to open innovation. Technological Forecasting and Social Change, 77 (2), pp. 335-343.

Weiss, A. (2002) A brief guide to competitive intelligence: How to gather and use information on competitors. Business Information Review, 19 (2), pp. 39-47.

Yoon, B. (2008) On the development of a technology intelligence tool for identifying technology opportunity. Expert Systems with Applications, 35 (1-2), pp. 124-135.

Yoon, J. \& Kim, K. (2012) TrendPerceptor: A property-function based technology intelligence system for identifying technology trends from patents. Expert Systems with Applications, 39 (3), pp. 2927-2938. 